\title{
Seebri Breezhaler (glikopironis) - didelio afiniteto inhaliuojamasis anticholinerginis vaistas LOPL gydyti
}

\author{
Kristina Biekšienè \\ LSMU MA Pulmonologijos ir imunologijos klinika
}

Reikšminiai žodžiai: lètinė obstrukcinẻ plaučių liga, glikopironis, anticholinerginis.

Santrauka. Klinikineje praktikoje pradètas vartoti naujas didelio afiniteto inhaliuojamasis ilgai veikiantis anticholinerginis bronchus plečiantis vaistas glikopironio bromidas (glikopironis). Tai miltelinis vieną kartą per parą vartojamas vaistas, patvirtintas LOPL gydyti. Glikopironiui būdinga greita veikimo pradžia - jo bronchus plečiantis poveikis pasireiškia per 5 minutes po pirmosios dozės inhaliacijos. Bronchus plečiantis glikopironio bromido poveikis trunka 24 valandas ir nesilpnèja vaistą nuolat vartojant ilgą laiką. Glikopironis yra toks pat efektyvus, saugus ir gerai toleruojamas kaip ir kitas vienintelis iki šiol turètas ilgo veikimo anticholinerginis vaistas tiotropio bromidas. Glikopironio bromidas irgi reikšmingai sumažina vidutinio sunkumo bei sunkių LOPL paūmèjimų skaičiu ir pagalbinių trumpo veikimo vaistų vartojimą. Taigi vieną kartą per parą vartojamas glikopironis (Seebri Breezhaler) gali būti alternatyva šiuo metu kompensuojamam ilgo veikimo anticholinerginiam vaistui tiotropiui LOPL sergantiems pacientams gydyti.

Lètinè obstrukcinè plaučių liga (LOPL) yra viena pagrindinių sergamumo ir mirtingumo priežasčių pasaulyje - ji ketvirta pagal dažnumą mirties priežastis. Numatoma, kad artimiausiu metu LOPL toliau plis, o mirtingumas nuo šios ligos didès. Europoje LOPL paplitimas yra 4-6 proc. [1]. Lietuvoje, turimų epidemiologinių tyrimų duomenimis, serga apie 3 proc. suaugusių gyventojų. Nuo LOPL Europoje kasmet miršta iki 300 tūkst. žmonių, Lietuvoje apie vieną tūkstantị [2].

LOPL - tai patologinè būklè, kurios įmanoma išvengti, ji pasireiškia nevisiškai išnykstančia kvejpavimo takų obstrukcija ir yra gydytina. Kvẻpavimo taku obstrukcija paprastai progresuoja, ji siejama su neịprastu plaučių atsaku uždegimu i i kkvepiamąsias kenksmingas daleles arba dujas, pirmiausia cigarečių rūkymą. Nors LOPL pažeidžia plaučius, ji sukelia ir reikšmingų sisteminių padarinių [3].

Pagrindiniai tikslai gydant LOPL yra sumažinti simptomus ir juos kontroliuoti, retinti paūmèjimų skaičių bei sunkumą, pagerinti sveikatos būklę bei padidinti fizinio krūvio toleravimą. LOPL gydymo pagrindas - inhaliuojamieji bronchus plečiantys vaistai [3]. Plačiai vartojami pirmos eilès bronchus plečiantys vaistai LOPL gydyti yra ilgo veikimo muskarininių receptorių antagonistai. Svarbiausiomis idealaus ilgai veikiančio anticholinerginio vais- to savybėmis laikomos šios: stiprus selektyvumas trečio tipo muskarininiams receptoriams (M3), ilgas veikimo laikas (geriausia 24 val.), greita veikimo pradžia, gebejjimas sukelti kliniškai reikšmingą bronchus plečiantị poveikị bei saugumas $[3,4,5]$.

Iki šiol vienintelis visame pasaulyje plačiai vartojamas ilgo veikimo anticholinerginis vaistas LOPL gydyti buvo tiotropis. Jis pagerina kvėpavimo funkciją, fizinio krūvio toleravimą, sveikatos būklę, sumažina dusulị, paūmèjimų skaičių bei mirtingumą, lyginant su placebu. Tačiau tiotropio veikimo pradžia yra lèta, jis sukelia šalutinius anticholinerginius reiškinius: burnos sausmę, šlapinimosi sutrikimus ir vidurių užkietejjimą [6].

Santykinai neseniai klinikinejje praktikoje pradètas vartoti kitas, naujai sukurtas didelio afiniteto inhaliuojamasis ilgai veikiantis anticholinerginis bronchus plečiantis vaistas glikopironio bromidas (glikopironis). Tai miltelinis vieną kartą per parą vartojamas vaistas, patvirtintas LOPL gydyti. Glikopironio bromido veikimas yra unikalus, lyginant su kitais anticholinerginiais vaistais LOPL gydyti. Vaistui būdinga greita veikimo pradžia, kuri yra greitesnè nei trumpo veikimo anticholinerginio preparato ipratropio bei ilgo veikimo anticholinerginio preparato tiotropio. Glikopironio bronchus plečiantis poveikis pasireiškia 
per 5 minutes po pirmosios dozès inhaliacijos, o ipratropio per 15 min., tiotropio - per 30 min. po inhaliacijos. Bronchus plečiantis glikopironio poveikis trunka 24 val., t. y. tiek pat kaip tiotropio. Kaip ir kiti inhaliuojamieji ilgai veikiantys anticholinerginiai bronchus plečiantys vaistai, glikopironis blokuoja M1 ir M3 muskarininius receptorius kvėpavimo takuose. Blokuodamas šiuos receptorius, glikopironis slopina bronchų lygiųjų raumenų susitraukimą (atpalaiduoja lygiuosius raumenis) [7, 8, 9, 10].

\section{GLIKOPIRONIO BROMIDO KLINIKINIŲ TYRIMŲ APŽVALGA}

Glikopironio bromido (Seebri Breezhaler) efektyvumas, saugumas gydant LOPL buvo patvirtintas klinikiniais tyrimais, kurių pagrindiniai čia apžvelgiami.

D'Urzo ir bendr. atliktame klinikiniame tyrime GLOW1 (angl. glycopyrronium bromide in COPD airways clinical study) buvo tiriamas glikopironio bromido efektyvumas, saugumas bei toleravimas gydant vidutinio sunkumo arba sunkia LOPL sergančius pacientus, lyginant su placebu [9]. Atsitikinès atrankos būdu i grupes suskirstyti pacientai $(\mathrm{n}=822)$ dvigubai aklu metodu buvo gydomi glikopironio bromidu $50 \mu$ g kartą per parą $(\mathrm{n}=552)$ arba placebu $(n=270) 26$ savaites. Pagrindinè tyrimo vertinamoji baigtis - forsuotas iškvèpimo tūris per pirmą sekundę $\left(\mathrm{FEV}_{1}\right)$ 12-tą gydymo savaitę. GLOW1 tyrimo rezultatai parodè, kad, gydant glikopironio bromidu, 12 savaitę FEV $\mathrm{F}_{1}$ buvo reikšmingai didesnis nei placebo grupeje (1 pav.). FEV padidejimas buvo pastebètas per pirmąsias 5 min. bei padidèjęs laikèsi 24 val. jau nuo pirmos gydymo dienos ir toks išliko visas 26 gydymo savaites. Gydant glikopironiu, reikšmingai sumažèjo dusulys, paūmèjimų rizika (31 proc.), pagalbinių vaistų vartojimas (0,46 ipurškimo per dieną) bei pagerejjo gyvenimo kokybè. Šalutinių reiškinių daugiau nustatyta placebo, o ne glikopironio grupeje.

Kitą, labai reikšmingą, klinikinị tyrimą GLOW2 paskelbè Kerwin su bendr. [11]. Jame buvo vertinamas glikopironio bromido efektyvumas ir saugumas gydant vidutinio sunkumo ir sunkią LOPL 52 savaites. Tai daugiacentris atsitiktiniu imčiu dvigubai aklas kontroliuojamasis tyrimas, kuriame glikopironio bromidas lygintas su tiotropiu (atvira grupè) ir placebu. Šiame klinikiniame tyrime dalyvavo 1066 pacientai, i gydymo grupes suskirstyti santykiu 2:1:1 (glikopironis, placebas, tiotropis). Tyrimą baigè 76 proc. pacientų. Pagrindinè GLOW2 tyrimo vertinamoji baigtis buvo $\mathrm{FEV}_{1}$ dydis po 12 gydymo savaičių. Šio klinikinio tyrimo rezultatai parode, kad 12-tą gydymo savaitę tiek glikopironis $(97 \mathrm{ml})$, tiek tiotropis $(83 \mathrm{ml})$ statistiškai reikšmingai padidino $\mathrm{FEV}_{1}$ lyginant su placebo grupe (2 pav.). Padidejęs FEV 1 glikopironio grupejje buvo nustatytas jau pirmos gydymo paros pabaigoje ir išliko padidèjęs 26-tą bei 52-tą gydymo savaitę, lyginant su placebu, ir buvo panašus i $\mathrm{FEV}_{1}$ padidejimą tiotropio grupeje (2 pav.). Labai svarbu tai, kad suvartojus pirmą dozę pirmą gydymo dieną po $5 \mathrm{~min}$. ir iki keturių valandų glikopironio bronchus plečiantis poveikis buvo reikšmingai didesnis nei tiotropio ir placebo grupėse (3 pav.). Tyrimo rezultatai rodo,

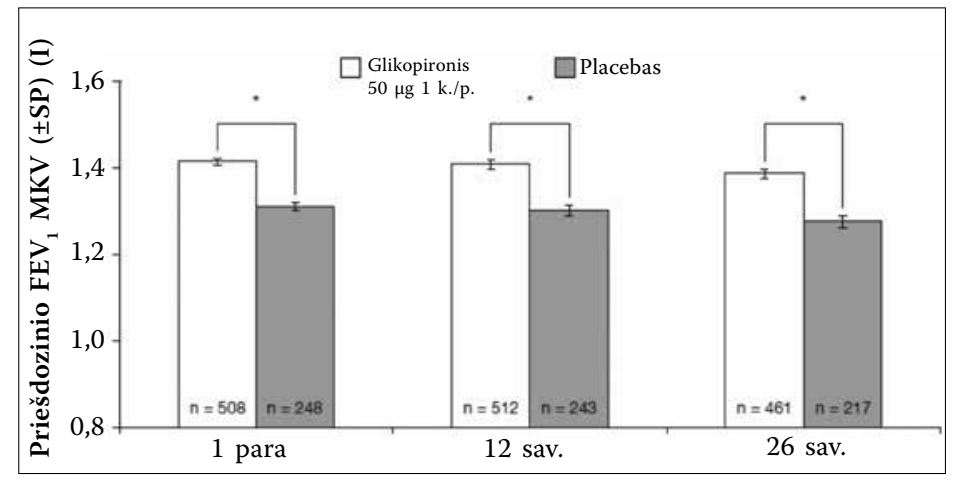

1 pav. Priešdozinis FEV 1 pirmą parą, 12-ą ir 26-ą savaitę

Duomenys yra MKV \pm standartiné paklaida. "p $<0,001$, palyginti su placebo poveikiu. Skirtumas tarp gydymo grupių pirmą parą - $105 \pm 10,9 \mathrm{ml}, 12$ savaitę $-108 \pm 14,8 \mathrm{ml}$ ir 26 savaitę - $113 \pm 16,5 \mathrm{ml}$. FEV - forsuoto iškvépimo tūris per pirmą sekundę; MKV - mažiausių kvadratų vidurkis, SP - standartinè paklaida.

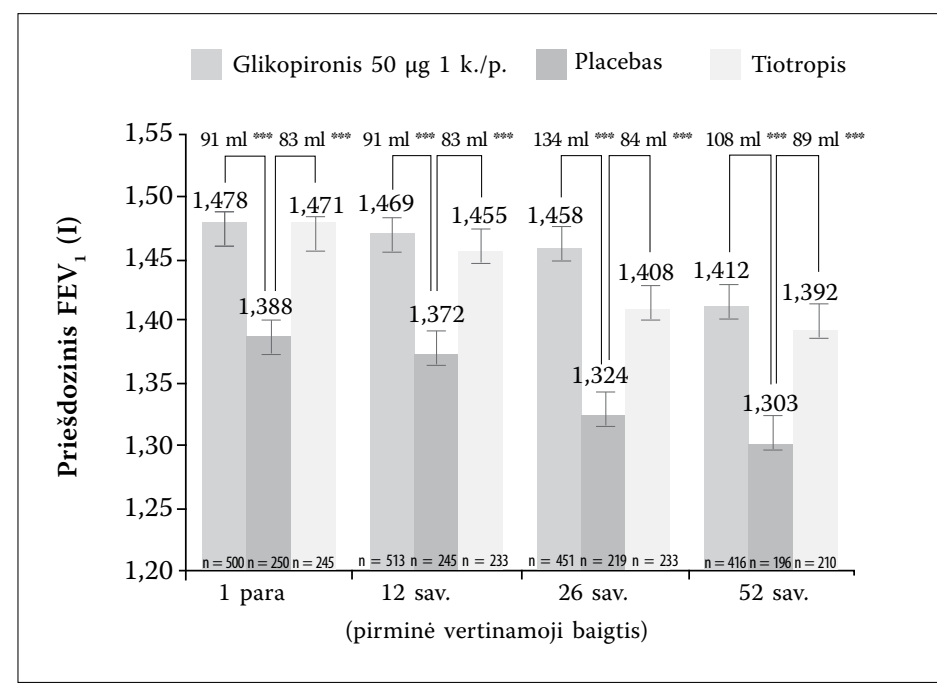

2 pav. Priešdozinis FEV pirmą parą, 12-ą, 26-ą ir 52-ą savaitę

Duomenys yra MKV \pm standartine paklaida. ${ }^{* * * *} \mathrm{p}<0,001$, palyginti su placebo poveikiu. ${ }^{+} \mathrm{p}<0,007$, palyginti su atvira tiotropio grupe. $\mathrm{FEV}_{1}$ - forsuoto iškvėpimo tūris per pirmą sekundę; MKV - mažiausių kvadratų vidurkis, SP - standartinè paklaida.

kad bronchus plečiantis glikopironio poveikis išlieka 24 val. nuo pirmos dienos iki 12-os ir 52-os gydymo savaitès (3 pav.). Glikopironis taip pat reikšmingai kaip tiotropis sumažino dusuli, vidutinių ir sunkių paūmèjimų skaičių (4 pav.), pagalbinių vaistų vartojimą (atitinkamai 0,37 inhaliacijomis per dieną $(p=0,039)$ ir $0,63(p=0,003))$ bei pagerino su sveikata susijusią gyvenimo kokybę, lyginant su placebu. Vertinant saugumą, pabréžtina, kad nepageidaujamo poveikio dažnumas gydant glikopironio bromidu (76,6 proc.) buvo panašus i gydymo tiotropio bromidu (74,2 proc.) ir labai nedaug skyrèsi nuo placebo (76,5 proc.). Taigi apibendrinus GLOW2 tyrimo rezultatus galima teigti, kad vieną kartą per parą vartojamam $50 \mu \mathrm{g}$ glikopironiui būdinga greita veikimo pradžia, jis išlieka efektyvus 24 val., yra saugus ir gerai toleruojamas vaistas. Glikopironio efektyvumas panašus it tiotropio, taigi gali būti alternatyvus ilgo veikimo anticholinerginis vaistas LOPL gydyti. Ivertinus GLOW2 tyrimo rezultatus, glikopironio bromidas buvo registruotas LOPL gydyti. 


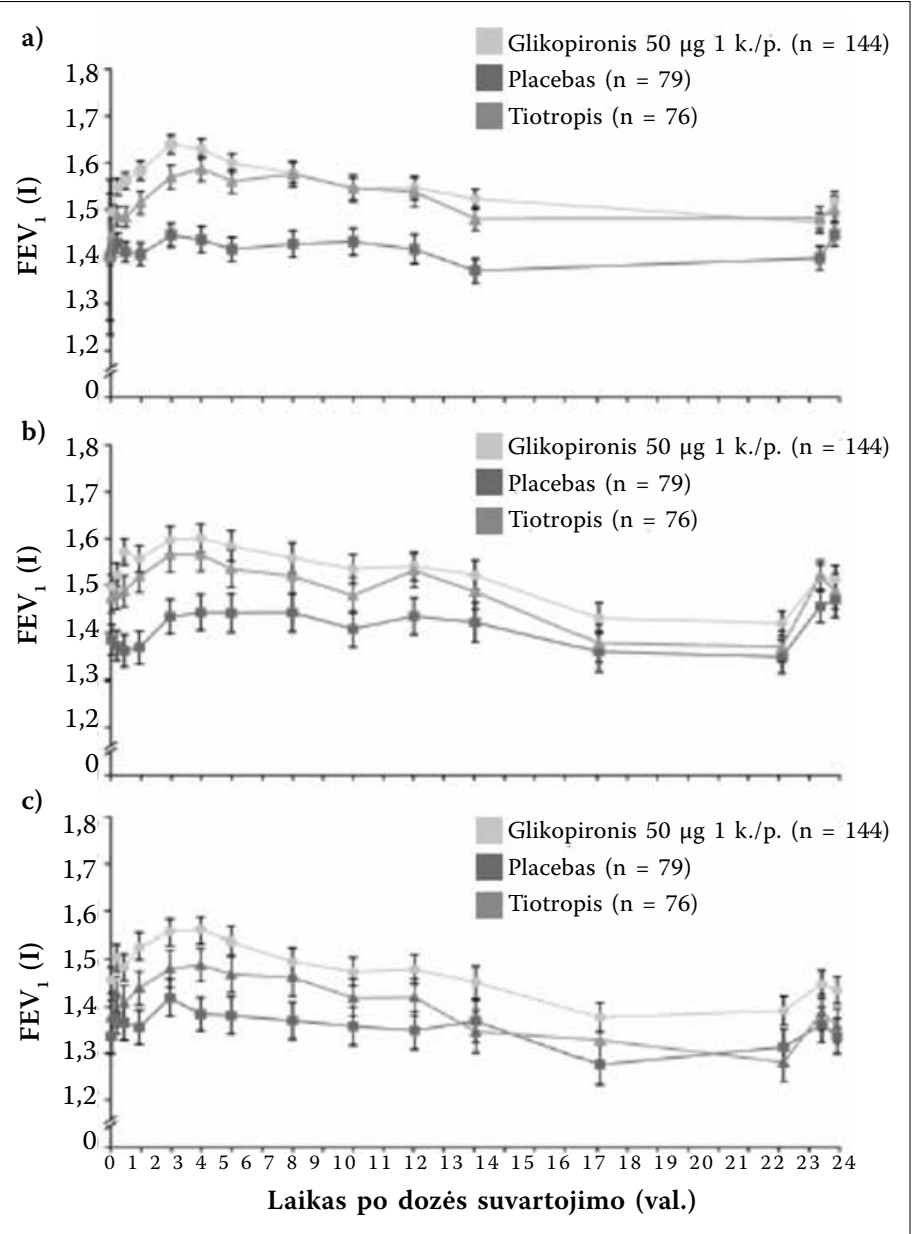

3 pav. Serijinè spirometrija a) pirmą parą, b) 26-ą sav., c) 52-ą sav.

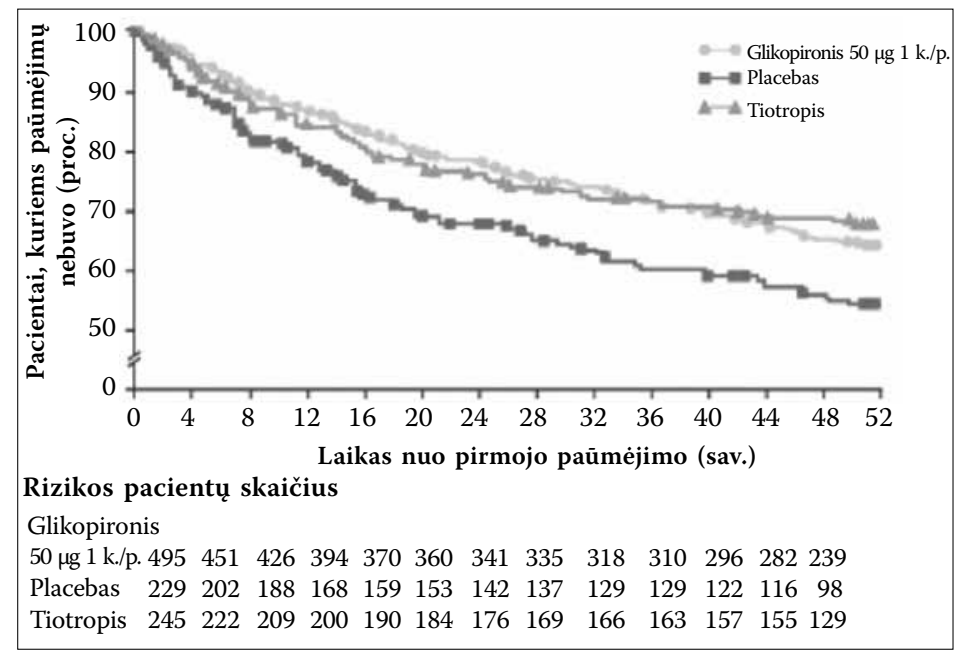

4 pav. Kaplano-Mejerio kreivè, vaizduojanti laiką iki pirmo vidutinio sunkumo ar sunkaus lètinès obstrukcinès plaučių ligos paūmèjimo

GLOW3 klinikiniame tyrime vertinta glikopironio ittaka fizinio krūvio toleravimui gydant vidutinio sunkumo ir sunkia LOPL sergančius pacientus tris savaites [12]. Tai klinikinis placebu kontroliuojamas kryžminis tyrimas, kuriame dalyvavo 108 pacientai. Pagrindinė vertinamoji baigtis - ištvermès laikas submaksimalaus fizinio krūvio metu. Nustatyta, kad glikopironis jau pirmą dieną page- rino fizinio krūvio toleravimą, lyginant su placebu, - ištvermè pailgèjo 43,1 sek. (10 proc.), o tyrimo pabaigoje (21 dieną) buvo ilgesnè net 88,9 sek. (21 proc.) (5 pav.). Po trijų gydymo glikopironiu savaičių sumažejo plaučių hiperinfliacija (FRC, RV, sGAW, TLC), lyginant su placebu (p $<0,05)$. Vertinant LOPL simptomus, 21-tą gydymo dieną Borg dusulio skalè gydant glikopironiu buvo sumažèjusi 20 proc. Gydymo grupejje reikèjo daug mažiau pagalbinių vaistų nei placebo grupejje.

Chapman su bendr. paskelbė GLOW5 klinikinị tyrimą, kuriame pirmą kartą buvo įvertintas glikopironio bromido efektyvumas ir saugumas, lyginant su aklai skiriamu tiotropiu, gydant vidutinio sunkumo ir sunkią LOPL 12 savaičių [13]. Pagrindiné vertinamoji baigtis $-\mathrm{FEV}_{1}$ po 12 gydymo savaičių. GLOW5 tyrimas patvirtino rezultatus, gautus GLOW2 tyrime, ir dar kartą parodè, kad glikopironio bromidas kaip ir tiotropis yra efektyvus, saugus, gerai toleruojamas vaistas LOPL gydyti. Šis tyrimas atskleidè, kad, ịvertinus kasdienių simptomų dienyną, bendras LOPL simptomų dažnumas glikopironio grupejje buvo reikšmingai mažesnis nei tiotropio ( $p=0,035)$.

Sykes su bendr. atliko tyrimą, kuriame vertino receptorių kinetikos įtaką glikopironio ir tiotropio veikimo pradžiai, trukmei bei terapiniam indeksui fiziologinėmis sąlygomis [14]. Šiuo tyrimu nustatyta, kad radioaktyviaisiais izotopais žymètu preparatų glikopironio ir tiotropio receptoriu disociacijos (atsipalaidavimo) pusperiodis yra gerokai trumpesnis (atitinkamai 11,4 ir 46,2 min.) nei buvęs nefiziologinėmis sąlygomis (atitinkamai 173 ir 462 min.) [15]. Šie rezultatai privertè suabejoti, kad ilgo veikimo anticholinerginių vaistų 24 val. klinikinio poveikio trukmè priklauso tik nuo receptoriu rezidencijos (vaisto ir receptoriaus jungties) laiko. Jau ankstesniu tyrimu rezultatai įrodè, kad glikopironio veikimo trukmè yra 24 val., nepaisant, kad jo susijungimo trukmé trumpesnè nei tiotropio [7, 10, 16]. Tolesni šio tyrimo duomenys atskleide, kad glikopironis M3 receptorius veikia selektyviau (10,7 karto) nei M2, o atsipalaidavimo laikas nuo M2 receptoriu yra trumpesnis (1,07 min.) nei nuo M3 (11,4 min.) (6 pav.). Tuo tarpu tiotropio selektyvumas M3 receptoriams yra tik 4,3 karto didesnis nei M2. Tyrimo duomenimis, glikopironio susijungimas su M4 ir M5 receptoriais taip pat trunka trumpiau nei tiotropio. Dèl šių skirtumų glikopironio terapinis indeksas gali būti geresnis nei tiotropio.

Apibendrinus atliktų tyrimų rezultatus galima teigti, kad vaistinis preparatas glikopironio bromidas (Seebri Breezhaler) yra šiek tiek efektyvesnis (statistiškai nereikšmingai) už dabar kompensuojamą vaistinị preparatą tiotropio bromidą vertinant $\mathrm{FEV}_{1}$ po 12 gydymo savaičių. Glikopironis pasižymi greita veikimo pradžia, t. y. bronchus plečiantis poveikis pasireiškia per 5 minutes po pirmosios dozès ir trunka 24 valandas. Tai turi teigiamą poveiki nuo rytinių simptomų ir sumažejusio aktyvumo kenčiantiems LOPL pacientams. Glikopironio bronchus plečiantis poveikis nesilpnėja vaistą vartojant ilgą laiką (6-12 mèn.). Glikopironis, kaip ir tiotropis, reikšmingai sumažino vidutinio sunkumo ir sunkių LOPL paūmèjimų 


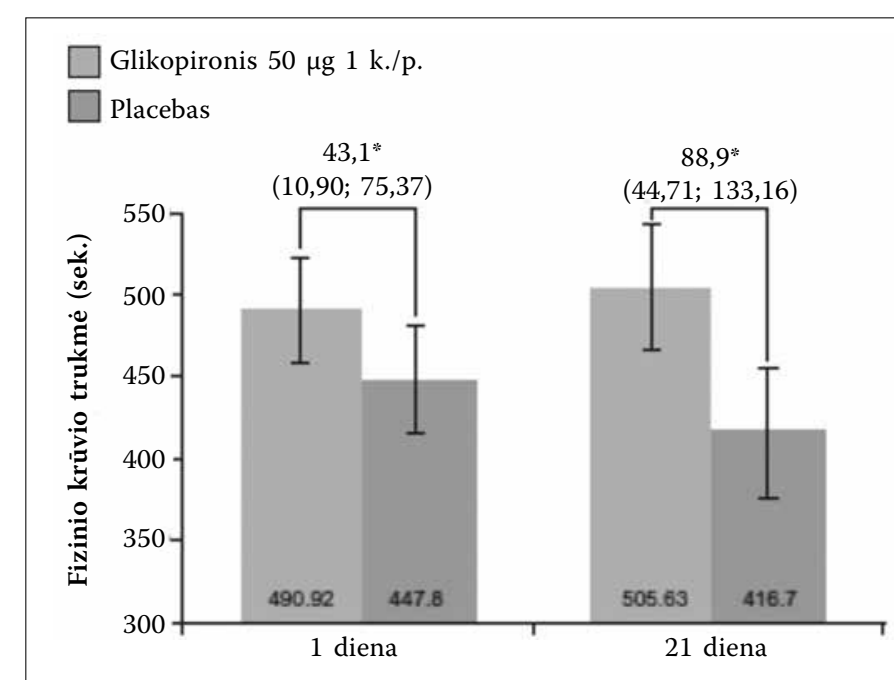

5 pav. Fizinio krūvio toleravimo trukmè ryte pirmą ir 21 dieną

Pacientai buvo tiriami per valandą po dozés pavartojimo.

Duomenys yra MKV (95 proc. PI) "p < 0,001. MKV - mažiausių kvadratų vidurkis PI - pasikliautinasis intervalas.

skaičiu bei pagalbinių trumpo veikimo vaistų vartojimą. Vertinant saugumą, pabrèžtina, kad glikopironio bromidas yra gerai toleruojamas. Nepageidaujamo poveikio dažnumas gydant glikopironio bromidu buvo panašus kaip gydant tiotropio bromidu ir labai nedaug skyrèsi nuo placebo. Taigi vieną kartą per parą vartojamas glikopironis (Seebri Breezhaler) gali būti alternatyva šiuo metu kompensuojamam ilgo veikimo anticholinerginiam vaistui tiotropiui LOPL sergantiems pacientams gydyti.

\section{SEEBRI BREEZHALER (GLYCOPYRRONIUM) - HIGH AFFINITY INHALED ANTICHOLINERGIC FOR THE TREATMENT OF CHRONIC OBSTRUCTIVE PULMONARY DISEASE}

\section{KRISTINA BIEKŠIENË \\ DEPARTMENT OF PULMONOLOGY AND IMMUNOLOGY ACADEMY OF MEDICINE LITHUANIAN UNIVERSITY OF HEALTH SCIENCES}

Keywords: chronic obstructive pulmonary disease, glycopyrronium, anticholinergic Summary. Glikopironium bromide (glycopyrronium) - the new, high affinity, inhaled, long acting anticholinergic bronchodilator started to use in clinical practice. It is dry-powder, once-daily used medication, approved for the treatment of chronic obstructive pulmonary disease (COPD). Glycopyrronium has rapid onset of action its bronchodilation effect starts within 5 minutes after the first dose inhalation. Bronchodilation effect of glycopyrronium sustains 24-hours and does not diminish using this medication continually for a long time. Glycopyrronium is effective, safe and well tolerated as the only known long-acting anticholinergic, tiotropium bromide. glycopyrronium significantly reduced moderate and severe COPD exacerbation rate and the use of short acting rescue medication. Once daily used glycopyrronium (Seebri Breezhaler) could be an alternative choice to currently reimbursed long acting anticholinergic tiotropium, for the treatment of patients with COPD.

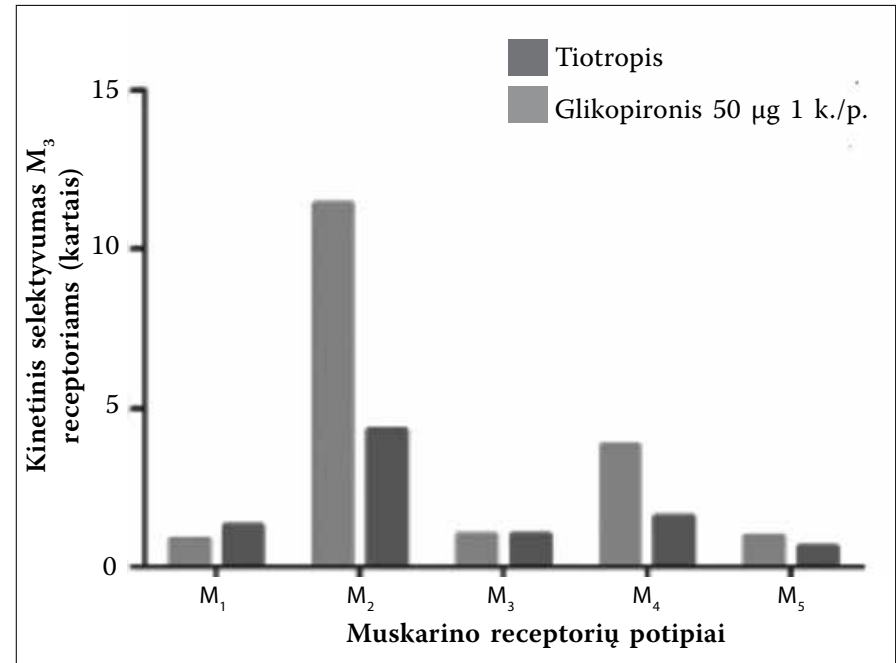

6 pav. Glikopironio ir tiotropio santykinis kinetinis selektyvumas M1-5 receptoriams

\section{LITERATŪRA}

1. Viegi G, Scognamilio A, Baldacci S, Pistelli F, Carrozzi L. Epidemiology of chronic obstructive pulmonary disease (COPD). Respiration 2001;68:4-19.

2. Malakauskas K, Sakalauskas R, Dudzevičius V, Šitkauskienè B, Milašauskienė Ž. Lètinès obstrukcinès plaučių ligos ir astmos paplitimas penkiuose Lietuvos rajonuose. (Prevalence of chronic obstructive pulmonary disease and asthma in five rural regions of Lithuania.) Lietuvos bendrosios praktikos gydytojas 2002;6:235-9.

3. GOLD: Global strategy for diagnosis, management and prevention of COPD. 2010 [http://www.goldcopd.com/].

4. Donohue JF . Minimal clinically important differences in COPD lung function.COPD 2: 2005; 111-124.

5. Vogelmeier C, Banerji D. NVA237, a long-acting muscarinic antagonist, as an emerging therapy for chronic obstructive pulmonary disease. Ther Adv Respir Dis 5: 2011;163-173.

6. Barr RG, Bourbeau J, Camargo CA, Ram FS. Tiotropium for stable chronic obstructive pulmonary disease: a meta-analysis. Thorax 61: 2006;854-862.

7. Verkindre $C$, Fukuchi Y, Fle'male A, Takeda A, Overend T, Prasad N, Dolker M. Sustained 24-h efficacy of NVA237, a once-daily long-acting muscarinic antagonist, in COPD patients. Respir Med 104: 2010;1482-1489.

8. Vogelmeier C, Verkindre C, Cheung D, Galdiz JB, Gu“ c,lu“ SZ, Spangenthal S, Overend T, Henley M, Mizutani G, Zeldin RK. Safety and tolerability of NVA237, a once-daily long-acting muscarinic antagonist, in COPD patients. Pulm Pharmacol Ther 23:2010;438-444.

9. D'Urzo A, Ferguson GT, Noord JA, Hirata K, Martin C, Horton R, Lu Y, Banerj $D$, Overend T. Efficacy and safety of once-daily NVA237 in patients with moderate-to-severe COPD: the GLOW1 trial. Respiratory Research 2011, 12:156.

10. Fogarty C, Hattersley H, Di Scala L, and Drollmann A (2011) Bronchodilatory effects of NVA237, a once daily long-acting muscarinic antagonist, in COPD patients. Respir Med 105:337-342. 